\title{
PENURUNAN TEKANAN DARAH MELALUI SARI KUNYIT PADA SESEORANG YANG MENGALAMI PREHIPERTENSI
}

\author{
Rizkya Nur Anisha ${ }^{1}$, Yuyun Priwahyuni ${ }^{2}$, Susi Erianti ${ }^{3}$ \\ 1,2,3 Program Studi Ilmu Keperawatan \\ STIKes HANG TUAH PEKANBARU 2018 \\ Email: Rizkyanuranisya28@gmail.com
}

\begin{abstract}
Abstrak
Prehipertensi adalah suatu kondisi menuju hipertensi. Prehipertensi di usia muda ditemukan sekitar 48,4\%. Penderita hipertensi usia $\geq 18$ tahun ditemukan sekitar $25,8 \%$ tahun 2013. Salah satu intervensi nonfarmakologis untuk hipertensi adalah sari kunyit. Penelitian ini bertujuan untuk menurunkan tekanan darah pada usia 20-30 tahun yang mengalami prehipertensi. Metode penelitian ini adalah pra ekperimental (one group pre-post design). Teknik sampling adalah Purposive sampling. Analisa yang digunakan adalah analisa univariat dan bivariat dengan mengunakan uji Wilcoxon untuk mengetahui tekanan darah pretest dan postest. Instrumen penelitian menggunakan lembar obeservasi. Hasil penelitian menunjukkan adanya pengaruh sari kunyit terhadap penurunan tekanan darah pada usia 20-30 yang mengalami prehipertensi dengan hasil $p$-value tekanan darah sistol yaitu $0.001(<0.05)$ dan untuk p-value tekanan darah diastol yaitu $0.002(<0.05)$. Sari kunyit efektif terhadap penurunan tekanan darah sistol dan diastol pada usia 20-30 tahun yang mengalami prehipertensi. Pihak Puskesemas Payung Sekaki dapat menjadikan kunyit sebagai refensi tanaman herbal yang berkhasiat.
\end{abstract}

Kata kunci: Prehipertensi, Penurunan Tekanan Darah, Sari Kunyit.

\begin{abstract}
Abstrak
Prehypertension is a condition that going to hypertension. Hypertension on the young age was found $48.4 \%$ around. People with hypertension at age 18th were found around 25,8 \% in 2013. One of nonpharmacologist for hypertension is tumeric Essences. Study aims to low the blood preassure for 20-30 age who have prehypertension. The research method used is pre-experimental sampling. Sampling technique is purposive sampling. The analysist used by univariat analysis and bivariat that using by wilcoxon test to know pretest adn postest of the blood preassure. Research intrument is using observation sheets. The resulst showed there is effect of tumeric juice on sistol blood preassure at 20-30 age who have hypertension with the result p-value blood preassure is $0.001(<0,05)$ and for p-value the diastol blood preassure is $0,002(<0,05)$. The tumeric juice is so affective to lowing the blood prassure on sistol and diastol at 20-30 age who habe prehypertension. The puskesmas in payung sekaki area can make tumeric can be used as a ference as a nutritious herbs.
\end{abstract}

Keywords: Prehypertension, Blood Pressure Reduction, Turmeric Essences.

\section{PENDAHULUAN}

Prehipertensi adalah suatu kondisi seseorang dalam katagori dalam rentang beresiko menderita hipertensi, biasanya seseorang yang mengalami prehipertensi akan memiliki tekanan darah 120-139 mmHg untuk sistol dan 80-89 mmHg untuk diastol (JNC VIII, 2014).
Penyakit hipertensi di Indonesia hampir menyerang semua kalangan tanpa terkecuali usia muda, pada usia $\geq 18$ tahun ditemukan penderita hipertensi sekitar $25,8 \%$ sedangkan untuk prehipertensi di usia muda ditemukan sekitar 48,4\%. Hasil persentase hipertensi berdasarkan golongan usia adalah sebagai berikut, usia 15-24 tahun sekitar 8,7\%, usia 
Rizkya Nur Anisha ${ }^{1}$, Yuyun Priwahyuni ${ }^{2}$, Susi Erianti ${ }^{3}$, Penurunan Tekanan Darah melalui Sari Kunyit Pada Seseorang yang mengalami Prehipertensi

25-34 tahun sekitar $14,7 \%$ dan usia 35-44 sekitar 24,8\% (Riskerdas, 2013).

Penderita hipertensi pada kirasan usia $\geq$ 18 tahun di provinsi Riau yang menderita hipertensi sebanyak 20,9\% (Kemenkes RI, 2014). Dari hasil data dinkes kota Pekanbaru Riau jumlah penderita hipertensi di kota pekanbaru pada tahun 2017 adalah sebesar 35.090 jiwa, dan jumlah terbesar berada di wilayah kerja puskesmas payung sekaki yaitu sebesar 3.708 jiwa.

Hipertensi dapat di obati dengan menggunakan pengobatan secara non farmakologi, salah satu pengobatan secara non farmakologi yaitu dengan mengunakan tanaman tradisional. Salah satu tanaman obat tradisional yang bermanfaat untuk menurunkan tekanan darah adalah kunyit, karena kunyit mempunyai banyak kandungan senyawa seperti minyak asiri, kurkumin, mineral fosfor dan kalium (Muti, 2017). Kalium merupakan salah satu mineral yang mengandung ion $\mathrm{K}^{+}$yang berfungsi sebagai penyeimbangan elektrolit dan cairan yang berguna sebagai natriuretik dan deuretik sehingga kalium mampu mengeluarkan natrium yang mengandung ion $\mathrm{Na}^{+}$dan cairan yang berada di dalam tubuh. Kalium mengakibatkan terjadinya vasodilatasi pada pembuluh darah, dimana vasodilatasi dapat menyebabkan turunnya resistensi perifer dan sentral sehingga dapat menyebabkan tekanan darah menjadi menurun (Kotchen \& Luft, 2006).
Berdasarkan hasil survey pendahuluan yang dilakukan oleh peneliti pada 15 orang dari kisaran usia 20- 25 tahun yang berada di wilayah kerja puskesmas payung sekaki kota Pekanbaru 8 diantarnya termasuk kedalam rentang prehipertensi dan 4 diantaranya masuk dalam rentang hipertensi ringan, 3 diantaranya berada dalam rentang normal, dari hasil survey awal tersebut kebanyakan dari mereka tidak pernah melakukan pencegahan seperti mengonsumsi obat herbal atau pun dengan cara lain.

Berdasarkan latar belakang tersebut tujuan dari penelitian adalah untuk mengetahui efektifitas sari kunyit terhadap penurunan tekanan darah pada penderita prehipertensi.

\section{METODE PENELITIAN}

Jenis penelitian ini adalah penelitian kuantitatif dengan menggunakan desain pra ekperimental (one group pre-post design). Responden berjumlah 17 responden, teknik sampling yang digunakan adalah Non probabiliy sampling, sampel ditentukan dengan teknik Purposive sampling yaitu menentukan sampel berdasarkan kriteria khusus yaitu seseorang yang menderita prehipertensi dengan rentang usia 20-30 tahun sesuai dari hasil sidang etik. Pengambilan data dengan menggunakan lembar observasi pre dan post tekanan darah responden, stetoskop dan Sphygmomanometer. Prosedur tidnakan yang harus di lakukan adalah responden harus menandatangani lembar persetujuan menjadi 
responden. Analisis yang digunakan adalah analisis univariat, dan bivariat.

\section{HASIL}

Karakteristik responden dilihat dari jenis kelamin dan usia. Ditemukan rata-rata usia klien yang ada pada kelompok ekperimen yang mengalami prehipertensi yaitu 23,82 tahun, usia tertinggi adalah 30 tahun dan usia terendah adalah 20 tahun. Untuk jenis kelamin 7 orang berjenis kelamin kali-laki dan 10 orang perempuan.

Pada tabel 1 menjelaskan tekanan darah sebelum intervensi dan tekanan darah sesudah intervensi.

Tabel 1

Distribusi hasil tekanan darah sebelum dan sesudah diberikan sari kunyit

\begin{tabular}{lcccccc}
\hline Variabel & $\mathbf{n}$ & Mean & Median & SD & $\begin{array}{c}\text { Minim } \\
\text { um }\end{array}$ & $\begin{array}{c}\text { Maksim } \\
\text { um }\end{array}$ \\
\hline $\begin{array}{l}\text { TD sistol } \\
\text { sebelum } \\
\text { intervensi }\end{array}$ & $\mathbf{1 7}$ & 133.00 & 135.00 & 4.000 & 125 & 138 \\
\hline $\begin{array}{l}\text { TD } \\
\text { Diasatol } \\
\text { sebelum } \\
\text { intervensi }\end{array}$ & 17 & 84.35 & 85.00 & 1.539 & 82 & 88 \\
\hline $\begin{array}{l}\text { TD sistol } \\
\text { sesudah } \\
\text { intervensi }\end{array}$ & 17 & 131.88 & 133.00 & 3.551 & 125 & 137 \\
\hline $\begin{array}{l}\text { TD } \\
\text { Diasatol } \\
\text { sesudah } \\
\text { intervensi }\end{array}$ & & & & & & \\
\hline
\end{tabular}

Tabel 1 menjelaskan mengenai rata-rata nilai tekanan darah sistol sebelum diberikan intervensi pemberian sari kunyit adalah sekitar $133.00 \mathrm{mmHg}$ sedangkan nilai rata-rata tekanan darah diastol adalah sekitar 84.35 mmHg. Hasil standar devesiasi untuk tekanan darah sistol yaitu 4.000 sedangkan untuk diastol yaitu 1.539. serta nilai tekanan darah sistol tertinggi dalah $138 \mathrm{mmHg}$ sedangkan untuk diastol tertinggi adalah $88 \mathrm{mmHg}$. Untuk tekanan darah sistol terendah adalah $125 \mathrm{mmHg}$ sedangakan untuk diastol terendah adalah $82 \mathrm{mmHg}$.

Tabel tersebut juga menjelaskan bahwa rata-rata nilai tekanan darah sistol setelah diberikan intervensi pemberian sari kunyit adalah sekitar $131.88 \mathrm{mmHg}$ sedangkan nilai rata-rata tekanan darah diastol adalah sekitar $83.53 \mathrm{mmHg}$. Hasil standar devesiasi untuk tekanan darah sistol yaitu 3.551 sedangkan untuk diastol yaitu 1.328 serta nilai tekanan darah sistol tertinggi dalah $137 \mathrm{mmHg}$ sedangkan untuk diastol tertinggi adalah 85 mmHg. Untuk tekanan darah sistol terendah adalah 125 sedangkan untuk diastol terendah adalah $80 \mathrm{mmHg}$.

Tabel 2

Efektifitas sari kunyit terhadap penurunan tekanan darah sistol.

\begin{tabular}{llcc}
\hline \multicolumn{1}{c}{ Variabel } & & n & P value \\
\hline Perbedaan & Negative & $14^{\mathrm{a}}$ & 0,001 \\
Nilai Tekanan & rank & $1^{\mathrm{b}}$ & \\
darah sistol & Positive rank & $2^{\mathrm{c}}$ & \\
sesudah dan & Ties & & \\
sebelum & & & \\
\hline
\end{tabular}

Tabel 2 di atas menjelaskan hasil yaitu 14 orang mengalami penurunan tekanan darah untuk sisitol. Namun ada 1 orang yang mengalami kenaikan tekanan darah untuk sistol, dan terdapat 2 orang tidak mengalami perubahan untuk tekanan darah sisitol Serta dari hasil uji statistik Wilcoxon menunjukan pvalue tekanan darah sistol yaitu $0.001 \quad(<0.05)$ maka dari itu H0 ditolak atau efektif. Sehingga 
Rizkya Nur Anisha ${ }^{1}$, Yuyun Priwahyuni ${ }^{2}$, Susi Erianti ${ }^{3}$, Penurunan Tekanan Darah melalui Sari Kunyit Pada Seseorang yang mengalami Prehipertensi

dapat dikatakan bahwa sari kunyit efektif untuk menurunkan tekanan darah pada usia dewasa muda yang mengalami prehipertensi.

Tabel 3

Perbedaan nilai tekanan darah diastol sebelum dan sesudah pemberian sari kunyit

\begin{tabular}{llcc}
\multicolumn{1}{c}{ Variabel } & & n & P value \\
\hline Perbedaan & Negative & $11^{\mathrm{d}}$ & 0.002 \\
Nilai Tekanan & rank & $0^{\mathrm{e}}$ & \\
darah diastol & Positive rank & $6^{\mathrm{f}}$ & \\
sesudah dan & Ties & & \\
sebelum & & & \\
\hline
\end{tabular}

Tabel 3 menunjukan hasil yaitu 11 orang mengalami penurunan tekanan darah untuk diastol. Dan tidak ada yang mengalami kenaikan tekanan darah. Serta dari hasil uji statistik Wilcoxon menunjukan p-value tekanan darah diastol yaitu $0.002(<0.05)$ maka dari itu H0 ditolak atau efektif. Sehingga dapat dikatakan bahwa sari kunyit efektif untuk menurunkan tekanan darah pada usia dewasa muda yang mengalami prehipertensi.

\section{PEMBAHASAN}

Berdasarkan hasil penelitian ini dapat disimpulkan bahwa sari kunyit efektif untuk menurunkan tekanan darah pada seseorang yang mengalami prehipertensi. Teori Kotchen dan Luft (2006), yang menyatakan tentang kunyit tinggi akan kandungan kalium dimana kalium mampu menghambat pelepasan renin hal ini mengakibatkan perubahan aktivitas sistem renin angiotensin dan mampu mengatur saraf perifer dan setral yang dapat mempengaruhi tekanan darah. Selain itu kalium juga berfungsi sebagai penyeimbangan elektrolit dan cairan yang berguna sebagai natriuretik dan deuretik sehingga kalium mampu mengeluarkan natrium yang mengandung ion $\mathrm{Na}^{+}$dan cairan yang berada di dalam tubuh sehingga memicu terjadinya penurunan tekanan darah.

Hasil penelitian ini sejalan dengan penelitian Mukti (2017) yang berjudul "Pengaruh parutan kunyit pada penurunan hipertensi di Kelurahan Barokah Kecamatan Purwokerto Selatan Kabupaten Banyumas" dimana Penelitian ini dilakukan selama 6 hari berturut-turut agar didapatkan hasil yang sangat signifikan hasilnya menunjukan ratarata nilai tekanan darah sebelum perlakuan 163,08 mmHg untuk tekanan sistol dan 107,69 mmHg untuk tekanan diastol. Dan setelah dilakukan intervensi maka hasil rata- rata tekanan darah menjadi $152,32 \mathrm{mmHg}$ untuk sistol dan 98,48 mmHg untuk hasil diastol. Sehingga dapat diindetifikasikan bahwa ratarata tekanan darah sebelum intervensi lebih tinggi dibandingkan tekanan darah setelah dilakukan intervensi.

Penelitian ini sesuai dengan penelitian yang dilakukan oleh Suryono (2012), yang bertujuan untuk menurunkan hipertensi menggunakan kunyit, dengan jumlah sampel 15 responden yang dilakukan selama 6 hari berturut-turut di Dusun Pandansari Kecamatan Purwosari Kabupaten Kediri. Hasil penelitian tersebut didapatkan rata-rata tekanan darah sistol sebelum adalah 151,33 $\mathrm{mmHg}$ dan diastol sebelum adalah $90,33 \mathrm{mmHg}$ dan sesudah dilakukan intervensi rata-rata tekanan 
darah menjadi $134 \mathrm{mmHg}$ untuk sistol dan 82,67 mmHg untuk diastol. Dapat diindetifikasikan bahwa rata-rata tekanan darah sebelum lebih tinggi dari pada rata-rata tekanan darah seletah dilakukan intervensi.

\section{SIMPULAN}

Hasil uji statistik didapatkan 14 orang mengalami penurunan tekanan darah untuk sisitol dan 11 orang mengalami penurunan untuk diastol, namun ada 1 orang mengalami kenaikan tekanan darah untuk sistol dengan $p$ value tekanan darah sistol yaitu $0.001(<0.05)$ dan untuk $p$-value tekanan darah diastol yaitu $0.002(<0.05)$ yang berarti H0 gagal ditolak atau efektif. Hal ini menunjukkan bahwa pemberian sari kunyit efektif untuk menurunkan tekanan darah.

\section{SARAN}

Diharapkan puskesmas hendaknya mempromosikan tanaman kunyit kepada warga sekitar untuk menanamnya ataupun tanaman lain sebagai apotek hidup dalam potpot di sekitar rumah mereka. Selain itu puskesmas hendaknya menghimbau masyarakat untuk melakukan pemeriksaan tekanan darah minimal setiap satu bulan sekali agar penderita prehipertensi dapat mengantrol tekanan darahnya. Diharapkan bagi peneliti selanjutnya dapat meneliti sari kunyit dengan desain quasi ekperimen disertai dengan kelompok kontrol karena pada penelitian ini hanya menggunkan desain yang masih sederhana tanpa kelompok kontrol. Selain itu peneliti selanjutnya dapat melakukan intervensi pemberian kunyit selama 6 hari bertut-turut agar mendapatkan hasil yang sangat signifikan dan memiliki manfaat bagi tubuh.

\section{DAFTAR PUSTAKA}

Anonim,(1998). Undang-Undang Nomor 13 Tahun 1998 Tentang Kesejahteraan Lanjut Usia.

Beavers. (2008). Tekanan darah. Jakarta: Dian Rakyat.

Corwin, Elizabeth. J. (2009).Buku Saku Patofisiologi Corwin. Jakarta: Aditya Media

Depkes RI. 2010. Pedoman Pembinaan Kesehatan Lanjut Usia bagi Petugas Kesehatan. Jakarta: Depkes.

Elizabeth B. Hurluck. (1997). Psikologi Perkembangan Suatu Pendekatan Sepanjang Rentang Kehidupan. Jakarta: Erlangga

Haryono, Rudi., \& Setianingsih, Sulis. 2013. Awas Musuh-Musuh Anda Setelah Usia 40 Tahun Waspada Terhadap Penyakit Stroke, Darah Tinggi, Asam Urat, Dan Jaga Pola, Hidup Sehat. Yogyakarta: PT Goysen Publishing.

Kementerian kesehatan RI (2014). Pusat Data dan Informasi. Jakarta selatan Kowalak, J, dkk. (2011) . Buku Ajar Patofisiologi. Jakarta : EGC

Potter, P.A, Perry, A.G. (2005). Buku Ajar Fundamental Keperawatan: Konsep, Proses, dan Praktik. Edisi 4 Volume 2. Alih Bahasa: Renata Komalasai dkk. Jakarta: EGC

Prasetyono Sunar, Dwi. (2012). A-Z Daftar Tanaman Obat Ampuh di Sekitar Kita. Jogjakarta: Flashbooks.

Price, A. Sylvia, Lorraine Mc. Carty Wilson. (2006). Patofisiologi: Konsep Klinis Proses-proses Penyakit, Edisi 6, (terjemahan), Peter Anugrah, EGC, Jakarta 
Rizkya Nur Anisha ${ }^{1}$, Yuyun Priwahyuni ${ }^{2}$, Susi Erianti ${ }^{3}$, Penurunan Tekanan Darah melalui Sari Kunyit Pada Seseorang yang mengalami Prehipertensi

Said, Ahmad.( 2007). Khasiat dan manfaat kunyit. Jakarta: Sinar Wadja Lestari.

Sedarmayanti.(2009). Sumber Daya Manusia dan Produktivitas Kerja. Bandung: CV Mandar Maju.

Setiawan, Dalimartha. (2008). 1001 Resep Herbal. Jakarta : Penebar Swadaya

Sherwood, L. (2012). Fisiologi Manusia dari Sel ke Sistem . Edisi 6. Jakarta : EGC.

Suprajitno.(2012). Asuhan Keperawatan Keluaraga Aplikasi dalamPraktik. Jakarta: EGC

Wijayakusuma, Hembing \& Dalimartba, Setiawan.(2000). Ramuan Tradisional Untuk Pengobatan Darah Tinggi. Cetakan IV. Jakarta

Azizah, B., \& Salamah, N. (2013). Standarisasi Parameter Non Spesifik dan Perbandingan Kadar Kurkumin Ekstrak Etanol dan Ekstrak Terpurifikasi Rimpang Kunyit. Pharmaciana, 3(1). Diakses pada tanggal 6 febuari 2018 dan diiperoleh dari https://scholar.google.co.id/scholar?hl=en \&as $\mathrm{sdt}=0 \% 2 \mathrm{C} 5 \& \mathrm{q}=$ STANDARISASI+P ARAMETER+NON+SPESIFIK+DAN+P ERBANDINGAN+KADAR+KURKUMI N+EKSTRAK+ETANOL+DAN+EKSTR AK+TERPURIFIKASI+RIMPANG+KU NYIT+STANDARDIZATION\&btnG

Fitriani, D. T. (2013). Efektifitas Temulawak Dalam Menurunkan Tekanan Darah Pada Lansia Di UPT Panti Sosial Tresna Werdha Mulia Dharma Kabupaten Kubu Raya. Diakses pada tanggal 25 januari 2018 dan Diperoleh dari https://scholar.google.co.id/scholar?hl=en \&as_sdt $=0 \% 2 \mathrm{C} 5 \& \mathrm{q}=$ efektifitas+temulaw ak+untuk+hipertensi\&btnG $=$

Hartati, S. Y. (2013). Khasiat kunyit sebagai obat tradisional dan manfaat Lainnya. Warta Penelitian dan Pengembangan Tanaman Industri, 19(2), 5-9. Diakses pada tanggal 26 januari 2018 dan diperoleh dari https://scholar.google.co.id/scholar?hl=en \&as_sdt=0\%2C5\&q=khasiat+kunyit+seba gai+obat+tradisional+fan+manfaat+lainya \&btnG $=$

Joint Nasional Committee (2014). Seventh Report of the Joint National Committee on Prevention,Detection, Evaluation, and
Treatment of High Blood Pressure (JNC 8). Guideline, US: Department Of Health and Human Services. Diakses pada tanggal 26 maret 2018 dan diperoleh dari https://scholar.google.co.id/scholar?hl=en \&as_sdt=0\%2C5\&q=klasifikasi+hipertens $\mathrm{i}++\mathrm{JNC}+\mathrm{VII} \& \mathrm{btnG}=$

Lestari, D., \& Lelyana, R. (2010). Hubungan Asupan Kalium, Kalsium, Magnesium, dan Natrium, Indeks Massa Tubuh, serta Aktifitas Fisik dengan Kejadian Hipertensi pada Wanita Usia 30-40 Tahun (Doctoral dissertation, Program Studi Ilmu Gizi). Diakses pada tanggal 5 febuari 2018 dan dapat dari https://scholar.google.co.id/scholar?hl=en \&as_sdt $=0 \% 2 \mathrm{C} 5 \& \mathrm{q}=$ hubungan + asupan $+\mathrm{k}$ alium $\% 2 \mathrm{C}+\mathrm{kalsium} \% 2 \mathrm{C}+$ magnesium $\% 2$ $\mathrm{C}+$ dan+natrium $\% 2 \mathrm{C}+$ indeks+masa+tubuh $\% 2 \mathrm{C}+$ serta+aktifitas+fisik+dengan+kejadi an+hipertensi+pada+wanita+usia+3040+tahun\&btnG $=$

Muti, R.T. (2017). Pengaruh Parutan Kunyit Pada Penurunan Hipertensi Pada Lansia Di Kelurahan Barokah Kecamatan Purwokerto Selatan Kabupaten Banyumas. MEDISAINS, 15(2),84-90. Diakses pada tanggal 18 desember 2017 dan dapat dari https://scholar.google.co.id/scholar?hl=en \&as_sdt $=0 \% 2 \mathrm{C} 5 \& \mathrm{q}=$ =efektifitas+parutan+ kunyit+untuk+hipertensi\&btnG=

Nababan, L.Y. (2018). Faktor-Faktor Yang Berhungan Dengan Kejadian Prehipertensi Pada Usia Dewasa Diwilayah Kerja Puskesmas Pelabuhan Sambas Kota sibolga. Diakses pada tanggal 31 juli 2018 di dapat dari http://scholar.google.co.id/scholar?hl=id\& as_sdt $=052 \mathrm{c} 5 \& \mathrm{q}=$ takanan + darah + prehipe rtensi\&btnG=\#d=gs_cit\&p=\&u=\%2fschol ar\%3fq\%3dinfo\%3a8ngxSaqHh24j\%3Asc holar.google.com\%2F\%26output\%3Dcite 26\%3d3\%26hl\%3Did

Nugroho, A.E., Suhardjono,D., \& Margono, S.A. (2008). The vasodilatation effects of curcumin and isolated aortic of rats. INDONESIAN JOURNAL OF PHARMACY, 70-77. Diakses pada tanggal 3 april 2018 dan di dapat dari https://scholar.google.co.id/scholar?hl=id 
\&as_sdt=0\%2C5\&q=efek+vasodilatasi $+\mathrm{k}$ urkumin $\& b t n G=\# d=g s \quad c i t \& p=\& u=\% 2 F s c$ holar\%3Fq\%3Dinfo\%3A60Y3QPAwiUJ \%3Ascholar.google.com\%2F\%26output\% 3Dcite\%26scirp\%3D0\%26hl\%3Did

Riset Kesehatan Dasar (Riskesdas). (2013).Badan Penelitian dan Pengembangan Kesehatan Kementerian RI tahun 2013. Diakses: 19 Oktober 2014, di akses pada tanggal 3 januari 2018 dan didapat dari http://www.depkes.go.id/resources/downl oad/general/Hasil\%20Riskesda \%202013.pdf.

Simanjuntak, P. (2015). Studi Kimia Dan Farmakologi Tanaman Kunyit (Curcuma longa L) Sebagai Tumbuhan Obat Serbaguna. JURNAL ILMU PERTANIAN" AGRIUM", 17(2). Diakses pada tanggal 26 januari 2018 dan peroleh dari https://scholar.google.co.id/scholar?hl=en \&as_sdt=0\%2C5\&q=studi+kimia+farmak ologi+tanaman+kunyit $+\% 28$ cucurma+lon ga+L\%29+sebagai+tumbuhan+seba+guna $\underline{\& b \operatorname{tnG}}=$

Sugawara, J., Akazawa, N., Miyaki, A., Choi, Y., Tanabe, Y., Imai, T., \& Maeda, S. (2012). Effect of endurance exercise training and curcumin intake on central arterial hemodynamics in postmenopausal women: pilot study. American journal of hypertension, 25(6), 651-656. Diakses pada tanggal 10 januari 2018 dan dieproleh dari https://scholar.google.co.id/scholar?hl=en \&as_sdt=0\%2C5\&q=effect+of+edurace+e xercise+training+and+curcumin + intake+o n+centra\%3B+artrial+hemodynamics+in+ postmenopausal+women\&btnG $=$

Suryono, S. (2017). Keefektifan Campuran Mahkota Dewa, Jinten Hitam Dan Kunyit Putih Pada Hipertensi (Di Dusun Pandansari Kec. Purwosari Kab. Kediri Tahun 2010). Jurnal AKP, 3(1). Diakses pada tanggal 25 janiari 2018 dan peroleh dari https://scholar.google.co.id/scholar?hl=en \&as_sdt=0\%2C5\&q=efektifitas++campur an+mahkota+dewa+jinten+hitam+dan+ku nyit+putih+untuk+hipertensi\&btnG= 